\title{
Low birth weight is associated with maternal nevirapine based antiretroviral therapy in Abidjan, Côte d'Ivoire: the Ditrame Plus project and MTCT-Plus initiative (200I-2007)
}

\author{
Patrick Coffie*1, Renaud Becquet ${ }^{2}$, Besigin Tonwe-Gold ${ }^{1}$, Apollinaire Horo1, \\ Pety Touré 3 , Stéphane Blanche ${ }^{4}$, François Dabis² ${ }^{2}$ Valeriane Leroy ${ }^{2}$ and \\ Didier Ekouevi ${ }^{1}$
}

Address: ${ }^{1}$ ANRS DITRAME PLUS Project, PACCI Collaboration, Abidjan, Côte d'Ivoire, ${ }^{2}$ Unité INSERM 593, Institut de Santé Publique d'Epidémiologie et de Développement (ISPED), Université Victor Segalen, Bordeaux, France, ${ }^{3}$ ACONDA, MTCT-Plus programme, Abidjan, Côte d'Ivoire and ${ }^{4}$ Service de Pédiatrie, Centre Hospitalier Universitaire Necker Enfants Malades, Paris, France

* Corresponding author

from Fourth Dominique Dormont International Conference. Host-Pathogen Interactions in Chronic Infections

Paris, France. 13-15 December 2007

Published: 9 April 2008

Retrovirology 2008, 5(Suppl I):O19 doi:10.1186/1742-4690-5-SI-OI9

This abstract is available from: http://www.retrovirology.com/content/5/SI/OI9

(C) 2008 Coffie et al.; licensee BioMed Central Ltd.

\section{Background}

Pregnancy outcomes in women on antiretroviral treatment (ART) in low resource-settings are unknown. We investigate this issue within the Ditrame Plus project and MTCT-Plus Initiative in Abidjan.

\section{Methods}

All HIV-infected pregnant women with at least one delivery and eligible for ART were included. Between March 2001 and July 2003 when ART was not available, they received a short-course antiretroviral regimen (zidovudine (ZDV) + single-dose of nevirapine (sdNVP) or ZDV + lamivudine + sdNVP) (PMTCT Group) and between August 2003 and August 2007, they received a NVP-based ART therapy (ART Group). The following outcomes were studied: low-birth weight (LBW) $(<2500 \mathrm{~g})$, stillbirth and neonatal mortality. Women with multiple pregnancies were excluded. Factors associated with LBW were analysed using a logistic regression model.

\section{Results}

Overall, 326 HIV-1 infected women were included: 175 in the PMTCT Group with a median CD4 count 177 cells/ $\mathrm{mm}^{3}$ and 151 initiated ART for at least 28 days before delivery with median CD4 count 182 cells $/ \mathrm{mm}^{3}$. Still birth rate was $3.3 \%$ in the ART vs $2.9 \%$ in the PMTCT group, $(\mathrm{p}=0.84)$. The rate of LBW was $22.3 \%$ in the ART and $12.4 \%$ in the PMTCT group $(\mathrm{p}=0.02)$. The multivariate regression model $(n=309)$, ART was associated with LBW when adjusting on the CD4 count, WHO staging, maternal age and maternal body max index $(\mathrm{ORa}=2.53$, $\mathrm{p}=0.015$ ). The survival at 12 month in HIV-uninfected children was similar between the two groups (Log-Rank test, $\mathrm{p}=0.78)$. Neither LBW (ORa=1.5, $\mathrm{p}=0.38)$ nor the exposition to ART $(\mathrm{ORa}=1.1, \mathrm{p}=0.85)$ were associated with infant mortality.

\section{Conclusions}

ART initiated in pregnant women induced low birth weight compared to newborn exposed to PMTCT regimen despite a supplementation with multivitamin in all pregnant women. The proper effect of maternal HAART on child survival needs to be assessed. 